\title{
Pomegranate (Punica granatum L.) Peel Extract: Potential Cytotoxic Agent against Different Cancer Cell Lines
}

\author{
Otilija Keta $\oplus^{1}$, Milena Deljanin $\oplus^{2}$, Vladana Petković $\bigodot^{1}$, \\ Gordana Zdunić $\bigodot^{3}$, Teodora Janković $\bigodot^{3}$, Jelena Živković $\bigodot^{3}$, \\ Aleksandra Ristić-Fira $\odot^{* 1}$, Ivan Petrović $\bigodot^{1}$ and Katarina Šavikin $\bigodot^{3}$ \\ ${ }^{1}$ University of Belgrade, Vinča Institute of Nuclear Sciences, Mike Petrovića Alasa 12-14, 11001, \\ Belgrade, Serbia \\ ${ }^{2}$ College of Applied Sciences in Technical Studies and Technology, Kosančićeva 36, 37000 \\ Kruševac, Serbia \\ ${ }^{3}$ Institute for Medicinal Plant Research "Dr Josif Pančić", Tadeuša Košćuška 1, 11000 Belgrade, \\ Serbia
}

(Received November 14, 2019; Revised February 17, 2020; Accepted February 19, 2020)

\begin{abstract}
The aim of the present study was to investigate effects of pomegranate peel (PP) extract on different human cancer cell lines. MTT was performed to estimate cytotoxic effects of PP extract against HTB140, HTB177, MCF7, HCT116 human cancer cell lines and MRC-5 normal fibroblasts. Clonogenic assay was used to reveal cell survival after the treatment with PP extract. Cell cycle analysis was done using flow cytometry. Wound healing assay was applied to estimate inhibitory effects of PP extract on migration of cancer cells. The results showed that PP extract expressed selective cytotoxicity for cancer cells compared to normal cell line. Analyzed cancer cell lines displayed individual variations in sensitivity to PP extract reflected through changes in clonogenic survival, cell cycle distribution and migration, which may be due to the specific nature of each tested cell line. In conclusion, PP extract exhibits good inhibitory effects on tested cancer cell lines.
\end{abstract}

Keywords: Punica granatum L.; peel extract; phenolic compounds; cytotoxicity; cancer cells. (C) 2020 ACG Publications. All rights reserved.

\section{Introduction}

Pomegranate (Punica granatum L.), is known as medicinal plant since ancient times, and is also considered as a mystical plant [1]. It is fruit-bearing shrub which originates from Middle East and India [2]. Historically, pomegranate has well documented appreciation in many cultures as a symbol of longevity and health [3]. All parts of the tree, including peel, have particular application especially in traditional medicinal systems such as Chinese, Ayurvedic and Unani [4]. For example, in ethnomedicine it is used as a remedy for various pathological conditions such as diabetes, dysentery, malaria, dental plaque and intestinal infections $[5,6]$. Some of the modern uses of pomegranate include treatment of cardiovascular conditions [7], and cancer [8], in addition to the use in oral hygiene [9] and cosmetics [10]. Over the last few decades, accumulating scientific data reveal that antioxidant, anti-inflammatory and anti-cancer activity of pomegranate can be largely attributed to its high content of polyphenols. Lansky and Newman [11] concluded that pomegranate extracts could find clinical applications in many diseases where chronic inflammation is believed to play an essential etiology, such as cancer. Both, edible parts as well as nonedible peel are rich sources of bioactive ingredients. According to Trolox equivalent antioxidant capacity assay, antioxidant activity

\footnotetext{
* Corresponding author: E-Mail: aristic@ vin.bg.ac.rs
} 
of pomegranate juice is three times higher compared with green tea and red wine [12]. Pomegranate peel (PP) is significant natural source of phenolics such as ellagitannins, proanthocyanidins, and flavonoids. Among typical compounds, ellagic and gallic acids, punicalagin and punicalin are reported $[13,14,15]$. However, it has been shown that besides acting as antioxidants, polyphenols also show pro-oxidant activity, especially at higher concentrations $[16,17,18]$. For example, the prooxidant effects of curcumin and carvacrol have been demonstrated in both cancer and normal cells $[17,18]$.

It has been estimated that by 2030 , the number of new cancer cases will reach 26 million and there will be 17 million deaths caused by cancer per year [19]. Since cancer incidence rates are higher in elderly population, this can be attributed to demographic changes, i.e. growth and aging of population [20]. Although new cutting-edge therapies such as gene therapy and nanomedicine are coming to the scene, surgery, chemotherapy and radiotherapy remain the basis of cancer treatments available today. Modern management of cancer also practices multimodal therapy approach which includes the use of different combinations of anticancer agents [21, 22]. However, treatment outcome remains unsatisfactory due to the developed chemo-resistance and severe side effects on healthy tissue [23]. Slow growth is one of the features of many types of cancers that can be exploited in treatment strategy. For some tumors it can take decades before the onset of invasive disease, thus leaving opportunity for preventive interventions [20]. Hence, the future cancer treatments should be oriented to prevention as well as to discovery of the new chemical compounds with selective toxicity toward cancer cells. Ideally, the new drugs would also have the potential to reduce the harmful effects when combined with other treatment modalities, i.e. radiation [24]. Recently, the interest has been raised for pharmacologically safe, naturally derived compounds, such as plant polyphenols due to their potent antioxidant properties. Although still limited, ongoing research data suggest that phytochemicals can also serve as effective chemo- or radio-sensitizers in multimodal cancer therapy [25].

The aim of this works was to test cytotoxic properties of PP extract on different human cancer cell lines. Cytotoxic effects of the compound affecting cell viability and proliferation, as well as cell cycle distribution and migration were investigated. In order to estimate the effects of the extract on healthy tissue, PP extract was also tested on normal human lung fibroblast cells. Obtained data would serve as a starting point for the experiments including combined treatments of PP extract with various cancer therapeutic tools such as low and high ionizing radiation.

\section{Materials and Methods}

\subsection{Standards and Reagents}

Standard punicalin was purchased from Phytolab (Vestenbergsgreuth, Germany), punicalagin $(\alpha+\beta)$ from Sigma-Aldrich (Steinheim, Germany), while ellagic and gallic acids were obtained from Extrasynthese (Cedex, France). Reagents which were used for experimental procedures were analytical grade. Folin-Ciocalteu phenol reagent was acquired from Sigma-Aldrich, (Steinheim, Germany), while formic and orthophosphoric acid, sodium carbonate and methanol were purchased from Sigma-Aldrich (Chemie GmbH, Munich, Germany). Acetonitrile was HPLC grade (Merck, Germany).

\subsection{Plant Material}

Ripe fruits of wild growing pomegranate were harvested during November 2016 in village Do (Bosnia and Herzegovina). Manually separated peel was air-dried 4-6 days at room temperature and grounded prior extraction in a laboratory mill. The voucher specimen (No. N42/15) was deposited in the Institute for Medicinal Plants Research "Dr Josif Pancic", Belgrade.

\subsection{Extraction Procedure}

Extraction procedure was according to our previously published data [13]. Briefly, powdered pomegranate peel $(50 \mathrm{~g})$ was extracted with $50 \%$ ethanol in ultrasonic bath during $40 \mathrm{~min}$ at $60^{\circ} \mathrm{C}$. 
Obtained extract was filtered and evaporated to dryness by rotary evaporator (Büchi R-210, Flawil, Switzerland).

\subsection{Total Phenolics Content}

Total phenolic content was determined spectrophotometrically using Folin-Ciocalteu (FC) according to the method of Waterman and Mole [26]. Briefly, $200 \mu \mathrm{L}$ of properly diluted extract were mixed with $1 \mathrm{~mL}$ of diluted FC reagent (1:10). 800 microliters of sodium carbonate $(75 \mathrm{~g} / \mathrm{L})$ were added after $4 \mathrm{~min}$ and after $2 \mathrm{~h}$ of incubation at room temperature absorbance was measured at $765 \mathrm{~nm}$. For the preparation of calibration curve, gallic acid $(0-100 \mathrm{mg} / \mathrm{L})$ was used. The results were expressed as milligrams of gallic acid equivalents per gram of dry weight (mg GAE/g DW). Experiments were performed in triplicate. The results were obtained with Spectrophotometer Hewlett Packard 8453 (Waldbronn, Germany).

\subsection{Total Tannins Content}

Total tannins content was analyzed according to European Pharmacopoeia (Ph Eur 7.0) [27]. Briefly, properly diluted extract, with and without previous treatment with hide powder, was mixed with phosphomolybdotungstic reagent in alkaline medium. The absorbance was measured at $\lambda$ max $760 \mathrm{~nm}$ (UV-VIS Spectrophotometer HP 8453, Agilent Technologies, USA). The content of tannins is expressed as pyrogallol \%, w/w and was calculated from the difference in absorbance of total polyphenols (A1) and polyphenols not adsorbed by hide powder (A2), using following expression:

$$
(62.5(\mathrm{~A} 1-\mathrm{A} 2) \times \mathrm{m} 2) /(\mathrm{A} 3 \times \mathrm{m} 1)
$$

where $\mathrm{m} 1$ represents mass of the sample to be examined, in grams and $\mathrm{m} 2$ and $\mathrm{A} 3$, mass in grams and absorbance of pyrogallol, respectively. Experiments were repeated three times.

\subsection{Total Flavonoids Content}

Total flavonoid content was analyzed spectrophotometrically according to Zhishen, et al. [28]. Briefly, 100 microliters of extract were mixed with $4 \mathrm{~mL}$ of distilled water and $0.3 \mathrm{~mL} 5 \%$ sodium nitrite was added. $0.3 \mathrm{~mL}$ of $10 \%$ aluminum chloride was added after $5 \mathrm{~min}$. After $6 \mathrm{~min}, 2$ $\mathrm{mL}$ of $1 \mathrm{M}$ sodium hydroxide was added to the mixture and the mixture was diluted by the addition of $3.3 \mathrm{ml}$ of distilled water. The absorbance was measured at $510 \mathrm{~nm}$. Catechin was used as standard for the calibration curve. Total flavonoids content was expressed as mg catechin equivalents per gram of dry weight (mg/g DW). Experiments were repeated three times. Results were obtained with Spectrophotometer Hewlett Packard 8453 (Waldbronn, Germany).

\subsection{High Performance Liquid Chromatography}

HPLC analyses were carried out on Agilent 1200 RR HPLC (Waldbronn, Germany), equipped with DAD detector, analytical column Zorbax SB-C18 $(5 \mu \mathrm{m} ; 150 \mathrm{~mm} \times 4.6 \mathrm{~mm}$ i.d; column temperature $25^{\circ} \mathrm{C}$.). The injection volume was $5 \mu \mathrm{L}$. The mobile phase A was solution of orthophosphoric acid in water (1\% v/v) and mobile phase B was acetonitrile, flow rate was 1 $\mathrm{mL} / \mathrm{min}$. Gradient elution was employed according to the following scheme: $98-90 \%$ A (0-5 min); 90\% A (5-15 min); $90-85 \%$ A (15-20 $\mathrm{min}) ; 85-70 \%$ A (20-25 min); 70-40\% A (25-30 $\mathrm{min}) ; 40-0 \%$ A (30-34 min). Detection was done at 260 and $320 \mathrm{~nm}$. For the quantification, calibration curves of standards gallic and ellagic acid, punicalagin $(\alpha+\beta)$ and punicalin were used. The results were express as milligrams per gram of dry weight. Experiments were repeated three times.

\subsection{Cell Culture}

The following human cancer cell lines, HTB140 melanoma, HTB177 large cell lung carcinoma, MCF7 breast carcinoma, HCT116 colon carcinoma as well as MRC-5 normal lung fibroblasts, used in this study, were purchased from ATCC (Manassas, VA, USA). Cells were grown 
as monolayers in RPMI 1640 medium (Sigma-Aldrich Chemie GmbH, Steinheim, Germany) supplemented with $10 \%$ fetal bovine serum (Sigma-Aldrich Chemie $\mathrm{GmbH}$ ) and a mixture containing $5000 \mathrm{U}$ penicillin and $5 \mathrm{mg} / \mathrm{mL}$ streptomycin in $0.9 \%$ sodium chloride (Sigma-Aldrich Chemie $\mathrm{GmbH}$ ). The cells were maintained at $37^{\circ} \mathrm{C}$, in a humidified atmosphere of $5 \% \mathrm{CO} 2$ (Heraeus, Hanau, Germany).

\subsection{Cytotoxicity Testing (MTT Assay)}

For determination of cell viability loss after administration of PP extract, the MTT (3-(4,5dimethylthiazol-2-yl)-2,5-diphenyltetrazolium bromide) tetrazolium reduction assay was performed according to manufacturer's instructions (Sigma-Aldrich, Germany). Human cancer cell lines, as well as normal fibroblasts, were seeded at suitable number in microtiter plates with 96 wells (Sarstedt AG \& Co., Nümbrecht, Germany) and incubated overnight when different concentrations of PP extract were added to the wells. The $100 \mathrm{mg} / \mathrm{mL}$ stock solution of the plant extract was previously prepared in culture medium containing 5\% DMSO. Final concentrations of extract were obtained by diluting stock solution in RPMI medium. Therefore, final concentration of DMSO in samples did not exceed $0.1 \%$. Cells were treated with seven different concentrations of extract: $15.63,31.25,62.5,125,250,500$ and $1000 \mu \mathrm{g} / \mathrm{mL}$ for 24 and $48 \mathrm{~h}$. After that, cells were incubated with MTT $(0.5 \mathrm{mg} / \mathrm{mL})$ for 4 hours under standard culture conditions. For that time, in metabolically active viable cells, yellow MTT was reduced to purple formazan by mitochondrial dehydrogenase. After dissolving formazan crystals in DMSO (SERVA Electrophoresis GmbH, Heidelberg, Germany), absorbance was measured in an ELISA plate reader (Victor2 1420 Multilabel counter, Wallac, Turku, Finland), at a wavelength of $550 \mathrm{~nm}$. Experiments were performed in triplicates and repeated in three independent series. IC50 was calculated by non-linear regression analysis of the data with the ED50plus v1.0 Software (http://www.softlookup.com/download.asp?ID=2972). Using IC50 values obtained at $24 \mathrm{~h}$ and $48 \mathrm{~h}$, selectivity index (SI) was determined according to the formula:

$$
\text { SI= IC50(fibroblast cell line)/IC50(tumor cell line) }
$$

For the values SI>2 it is considered that PP extract is highly selective for malignant cells compared to normal cell line.

\subsection{Clonogenic Assay}

To estimate cell survival after the treatment with PP extract, clonogenic assay was performed. Briefly, cells were harvested by trypsinization ( $0.25 \%$ trypsin, Serva Feinbiochemica, Heidelberg, Germany) and seeded at a suitable number into the 6-well plates (Sarstedt AG \& Co., Nümbrecht, Germany). Exponentially growing cells were treated for $24 \mathrm{~h}$ with PP extract. Two concentrations (16 and $32 \mu \mathrm{g} / \mathrm{mL}$ ) were chosen for the treatment since it has been shown that for all cell lines used in this experiment these concentrations were lower than the IC50 values estimated by MTT assay. After the incubation at standard conditions $\left(37^{\circ} \mathrm{C}, 5 \% \mathrm{CO} 2\right)$ for 7 days, cells were fixed with methanol (Zorka Pharma, Hemija, d.o.o., Sabac, Serbia) and stained with 10\% Giemsa solution (Alkaloid A.D., Skopje, FYROM). More than 50 cells per colony were scored as a surviving cell. Survival was calculated by comparing the number of colonies in samples treated with PP extract with the number of colonies in the untreated control. Plating efficiency (PE) and surviving fraction of the cells after the treatment were calculated using subsequent formulas:

$\mathrm{PE}=$ no. of colonies formed/ no. of cells seeded $\mathrm{x} 100 \%$

$\mathrm{SF}=$ no. of colonies formed after treatment $/$ no. of cells seeded $\mathrm{x} \mathrm{PE}$

\subsection{Cell Cycle Analysis}

In order to estimate changes in cell cycle, cells were treated with $16 \mu \mathrm{g} / \mathrm{mL}$ PP extract and analyzed 24 and $48 \mathrm{~h}$ later. Approximately $1 \times 10^{6}$ cells were fixed in cold $70 \%$ ethanol and 
incubated with $1 \mathrm{mg} / \mathrm{mL}$ ribonuclease A (Rnase A, Sigma-Aldrich Chemie $\mathrm{GmbH}$ ), for $15 \mathrm{~min}$ at $37^{\circ}$ C. After incubation, the cells were stained with $50 \mu \mathrm{g} / \mathrm{mL}$ of propidium iodide (PI, Sigma-Aldrich Chemie $\mathrm{GmbH}$ ), and 10000 cells per sample were analyzed on CyFlow ${ }^{\circledR}$ flow cytometer (Partec $\mathrm{GmbH}$, Münster, Germany). The results were analyzed using FloMax ${ }^{\circledR}$ software.

\subsection{Analysis of Cell Migration}

Cells were seeded in 12-well plates in triplicate and cultured to form a confluent monolayer. A scratch was made using $200 \mu \mathrm{L}$ pipette tip and detached cells were removed by washing with PBS. As for the cell cycle analysis, the same non-toxic concentration of extract $(16 \mu \mathrm{g} / \mathrm{mL})$ was used for the treatment. Images were captured with inverted microscope (Carl Zeiss, Jena, Germany) at the moment of treatment $(0 \mathrm{~h})$ and $24 \mathrm{~h}$ later. Photographs were analyzed using MRI Wound Healing Tool plugin in ImageJ software.

\subsection{Statistical Analysis}

All biological experiments were done at least in triplicate and were repeated tree times. Graphs were plotted using commercial SPSS version 20.0 or Origin8 software. Depending on data distribution statistical evaluation was performed by Student's t-test or one-way ANOVA with post hoc analysis of dose differences carried out by Tukey's test. Results were considered statistically significant for $\mathrm{p}<0.05$. The results are expressed as mean values with standard error of the mean (SEM).

\section{Results and Discussion}

\subsection{Chemical Analysis}

HPLC chromatogram of ethanol extract of pomegranate peel is presented in Figure 1. Chemical composition of the PP extract was analyzed spectrophotometrically for the determination of total phenols, tannins and flavonoids content (Table 1), as well as by HPLC method for the quantification of individual compounds (punicalin, punicalagin, ellagic and gallic acids) which is presented in Table 2 .

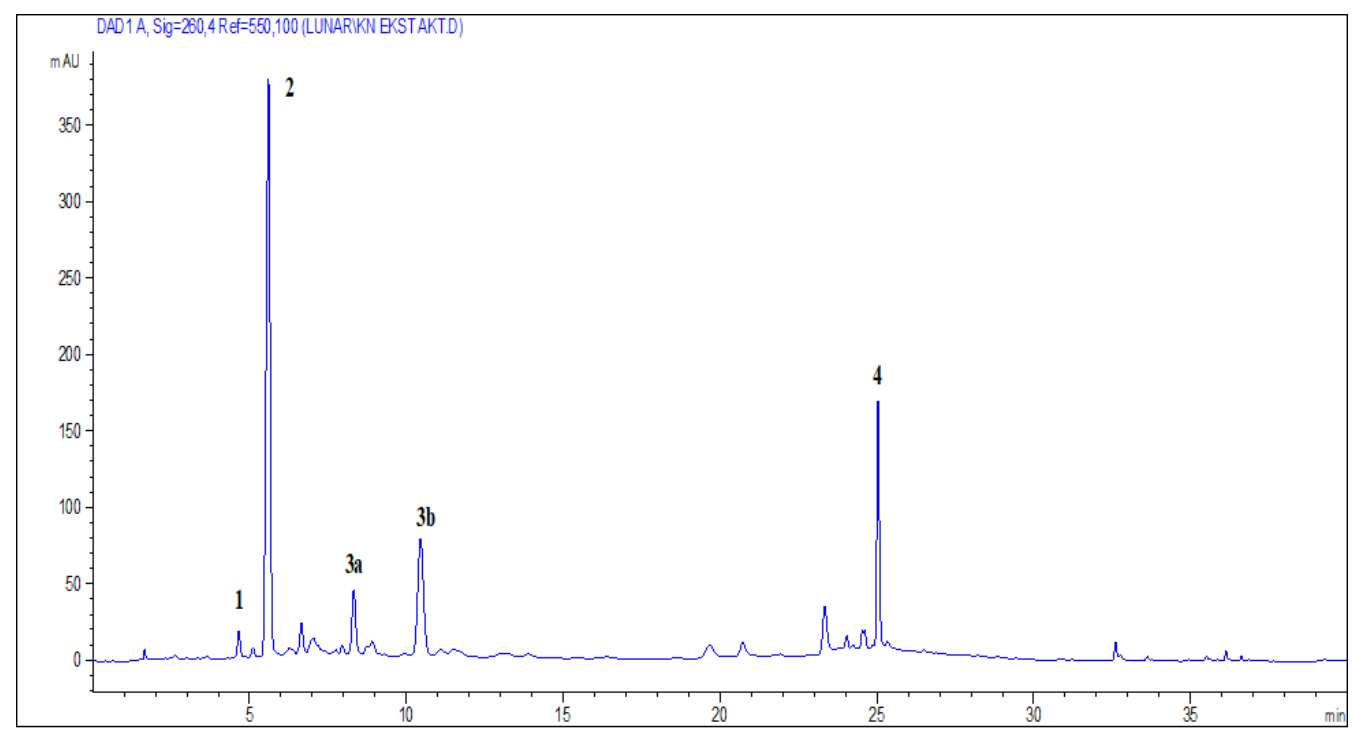

Figure 1. HPLC chromatogram of ethanol extract of pomegranate peel detected at $260 \mathrm{~nm}$ 1: Gallic acid; 2: Punicalin; 3a: $\alpha$ - Punicalagin; 3b: $\beta$ - Punicalagin; 4: Ellagic acid 
Table 1. Total phenolics, total flavonoids and total tannins content in dry pomegranate peel extract

\begin{tabular}{lc}
\hline Compounds & Content \\
\hline Total phenolics & $367.33 \pm 3.99 \mathrm{mg} \mathrm{GAE} / \mathrm{g} \mathrm{DW}$ \\
Total flavonoids & $6.06 \pm 0.37 \mathrm{mg}$ catechin/g DW \\
Total tannins & $27.52 \pm 1.21 \%$ \\
\hline
\end{tabular}

Table 2. HPLC quantification of dominant compounds in dry pomegranate peel extract.

\begin{tabular}{lc}
\hline Compounds & Content $(\mathbf{m g} / \mathbf{g ~ D W})$ \\
\hline Punicalagin $(\alpha+\beta)$ & $50.92 \pm 0.22$ \\
Punicalin & $182.41 \pm 0.86$ \\
Gallic acid & $6.11 \pm 0.02$ \\
Ellagic acid & $22.54 \pm 0.05$ \\
\hline
\end{tabular}

\subsection{Biological Response to PP Extract}

In this experimental setup, the effects of PP extract were analyzed on four human cancer cell lines derived from different tumors. Moreover, cytotoxicity was also tested on normal human fibroblasts in order to estimatethe effects of the extract on normal, healthy tissue. From a wide range of concentrations examined with MTT, 16 and $32 \mu \mathrm{g} / \mathrm{mL}$ PP extract were chosen for clonogenic assay so as to determine reproductive death of the cells after the treatment. Since under chosen experimental conditions $32 \mu \mathrm{g} / \mathrm{mL}$ PP extract in clonogenic assay for all cell lines showed strong killing effect, for cell cycle analysis and migration assay only the lower concentration of $16 \mu \mathrm{g} / \mathrm{mL}$ was used. In all experiments, incubation period with PP extract lasted for $24 \mathrm{~h}$ or $48 \mathrm{~h}$. After that period, biological assays were performed as indicated.

\subsubsection{Cytotoxic Effects of PP Extract}

Cytotoxicity profiles of PP extract in HTB140, HTB177, MCF7, HCT116 and MRC-5 cells are given in Figure 2. There was a statistically significant difference between groups as determined by one-way ANOVA. A Tukey post hoc test revealed dose-dependent increase of cytotoxicity induced by PP in all tested cell lines at both $24 \mathrm{~h}$ and $48 \mathrm{~h}$ time points. Concentrations of PP extracts higher than $62.5 \mu \mathrm{g} / \mathrm{mL}$ provoked a statistically significant increase in cytotoxicity compared to concentration of $16 \mu \mathrm{g} / \mathrm{mL}$.

Corresponding half maximal inhibitory concentration values (IC50) and degree of selectivity are presented in Table 3. According to the data obtained with MTT, for MRC-5 fibroblasts, rather high concentrations of extract were required to achieve 50\% drop in cell viability compared to cancer among tested cancer cell lines, HTB140 melanoma cells responded to extract quite similar to normal fibroblasts, with IC50 values rising from $\sim 118 \mu \mathrm{g} / \mathrm{mL}$ at $24 \mathrm{~h}$ to $\sim 179 \mu \mathrm{g} / \mathrm{mL}$ at $48 \mathrm{~h}$. Other cancer cell lines were more sensitive to PP extract. The IC50 value for HTB177 cells measured at $24 \mathrm{~h}$ was $\sim 55 \mu \mathrm{g} / \mathrm{mL}$, whilst, probably due to the loss of extract potency, detected IC50 values were almost twofold higher $(\sim 120 \mu \mathrm{g} / \mathrm{mL})$ at $48 \mathrm{~h}$. For HCT116 and MCF7 cells, an increase of extract toxicity was observed with prolonged incubation. Accordingly, for HCT116 cells, IC50 dropped from $\sim 75$ at $24 \mathrm{~h}$ to $\sim 40 \mu \mathrm{g} / \mathrm{mL}$ at $48 \mathrm{~h}$, though for MCF7 a milder decline of IC50 was detected $(\sim 39$ and $\sim 31$ $\mu \mathrm{g} / \mathrm{mL}$, respectively).

Degree of selectivity (selectivity index, SI) was expressed through comparison of normal and cancer cell response to PP extract and is given in Table 3. Measured at $24 \mathrm{~h}$, SI values for all cell lines were higher than 2 , indicating high specificity of the extract towards cancer cell lines. At $48 \mathrm{~h}$, SI was still high for MCF7 and HCT116 cells ( 6 and $\sim 5$, respectively). 


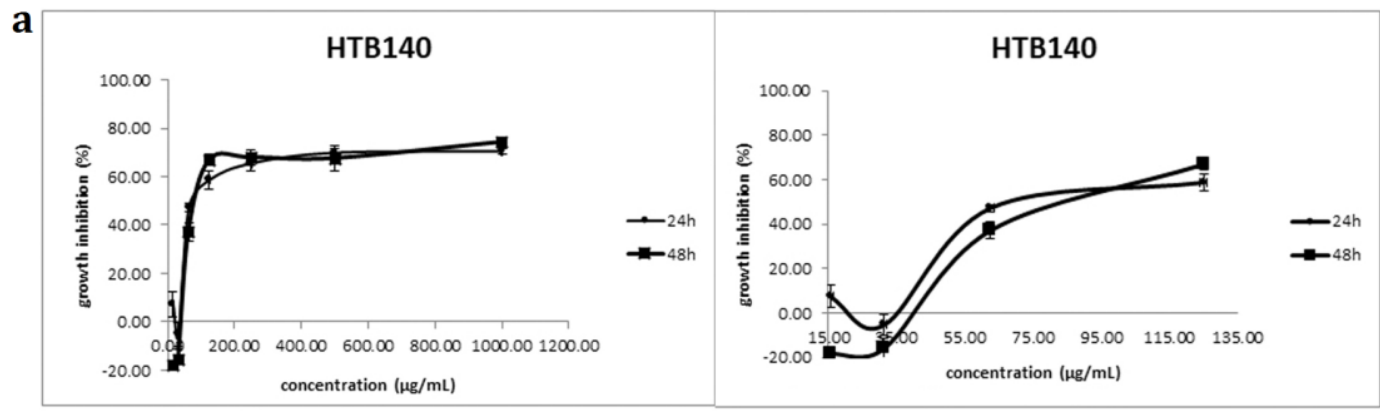

$\mathbf{b}$

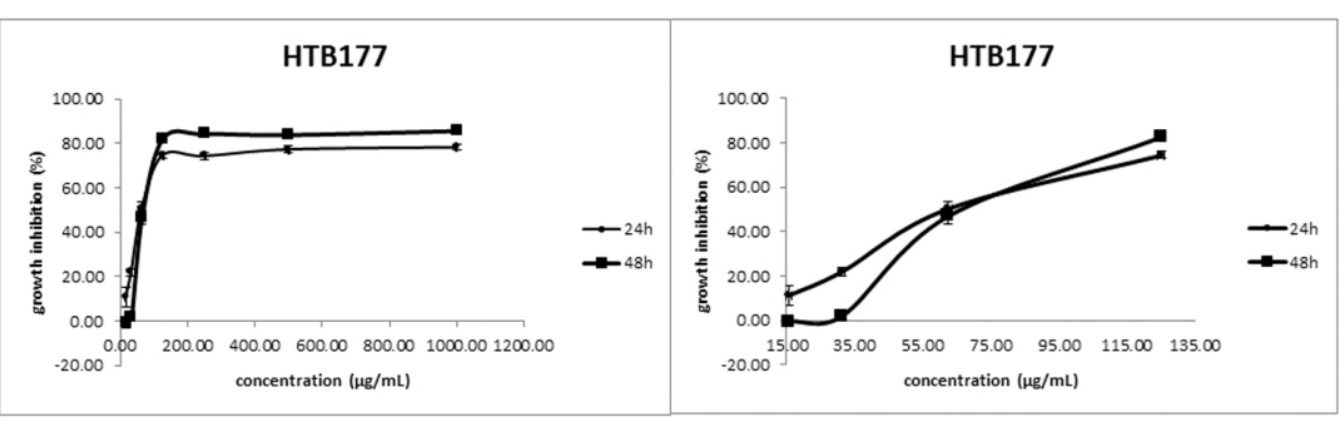

c

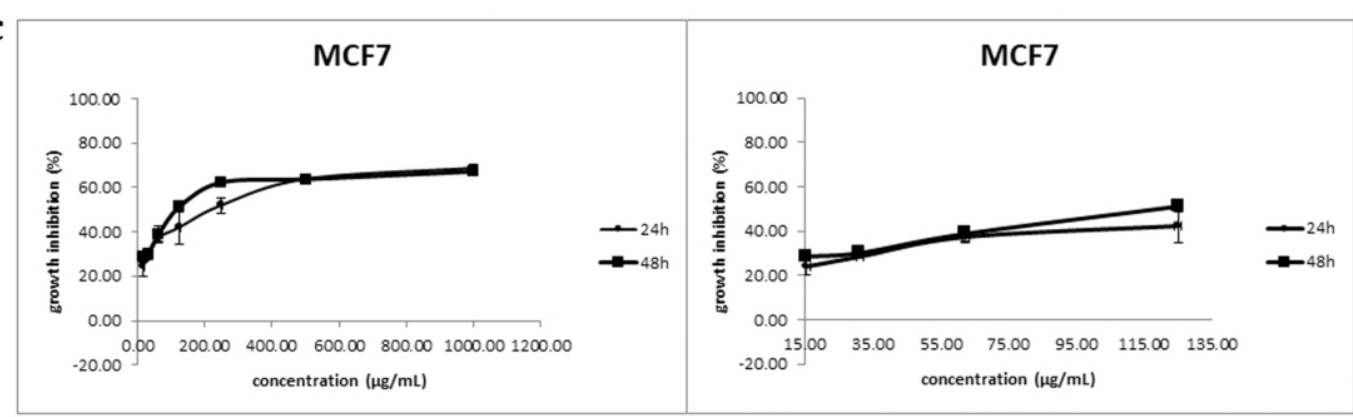

d

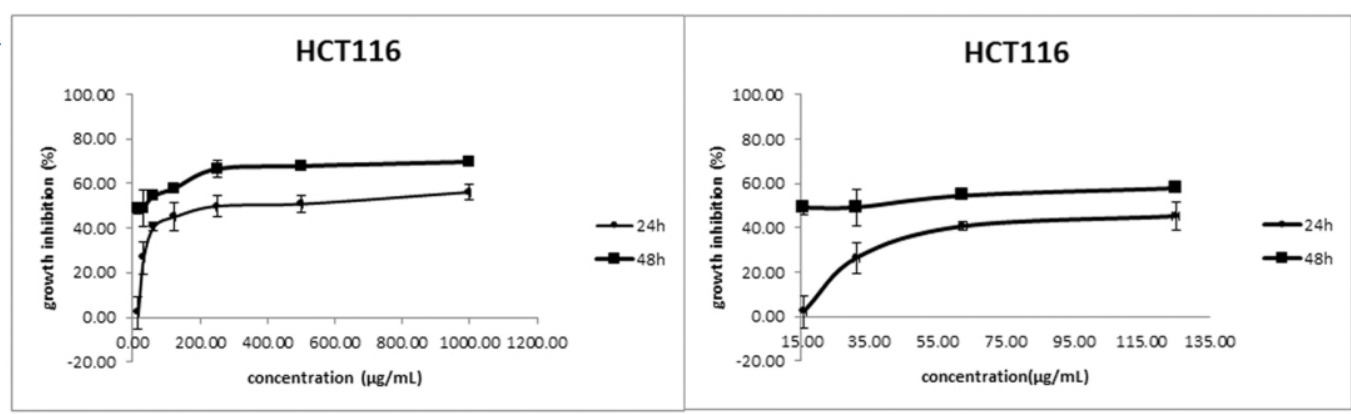

$\mathbf{e}$

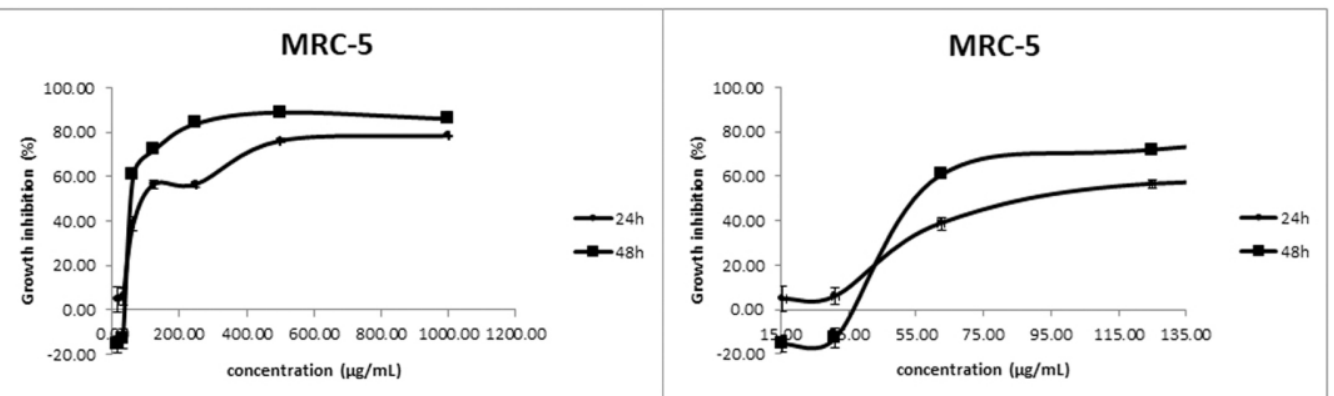

Figure 2. Growth inhibition of HTB140 cells

(a), HTB177 cells (b), MCF7 cells (c), HCT116 cells (d) and MRC-5 cells (E) after $24 \mathrm{~h}$ and $48 \mathrm{~h}$ treatment with $15.63,31.25,62.5,125,250,500$ and $1000 \mu \mathrm{g} / \mathrm{mL}$ PP extract measured by MTT assay. Enlarged scale is presented next to the corresponding figure. Results are expressed as mean \pm SEM (standard error of the mean). 
Table 3. Cytotoxic activity of pomegranate peel extract against cancer cell lines

\begin{tabular}{lrlll}
\hline Cell line & \multicolumn{2}{l}{ IC50 values \pm SEM } & \multicolumn{2}{l}{ SI (selectivity index) } \\
\hline & \multicolumn{1}{l}{$\mathbf{2 4 h}$} & $\mathbf{4 8 h}$ & $\mathbf{2 4 h}$ & $\mathbf{4 8 h}$ \\
\hline HTB140 & $117.57 \pm 1.99$ & $178.57 \pm 2.35$ & $1.42 \pm 0.02$ & $1.06 \pm 0.01$ \\
HTB177 & $55.15 \pm 1.09$ & $119.75 \pm 0.64$ & $3.02 \pm 0.06$ & $1.6 \pm 0.01$ \\
MCF7 & $38.92 \pm 2.34$ & $31.29 \pm 1.63$ & $4.28 \pm 0.26$ & $6.05 \pm 0.32$ \\
HCT116 & $74.85 \pm 2.99$ & $40.15 \pm 1.25$ & $2.23 \pm 0.09$ & $4.71 \pm 0.15$ \\
MRC-5 & $166.65 \pm 0.33$ & $189.15 \pm 0.05$ & 1 & 1 \\
\hline
\end{tabular}

* Selectivity index (SI) is estimated as the ratio between $\mathrm{IC}_{50}$ values of normal and cancer cells treated with PP extract, at corresponding time points ( 24 and $48 \mathrm{~h}$ ). Data were calculated by non-linear regression analysis using data obtained by MTT assay from cell samples treated with PP extract for 24 and $48 \mathrm{~h}$

\subsubsection{Effects of PP Extract on Cell Survival}

Considering the cytotoxicity data obtained by MTT assay (Figure 2), we have selected concentrations of $16 \mu \mathrm{g} / \mathrm{mL}$ and $32 \mu \mathrm{g} / \mathrm{mL}$ as optimal for the analysis of cell survival assuming that $\mathrm{PP}$ extract at higher concentrations would cause overkill. As presented in Figure 3, clonogenic assay showed high inhibitory effects of PP extract. Cells were treated for $24 \mathrm{~h}$ with the extract and colonies were counted 7 days later. Survival data showed that only HTB140 and HTB177 cells survived the lower concentration of $16 \mu \mathrm{g} / \mathrm{mL}$ PP extract. With SF $(16 \mu \mathrm{g} / \mathrm{mL})$ of 0.74 , HTB 177 cells were more resistant to the extract compared to HTB140 cells, having $\mathrm{SF}(16 \mu \mathrm{g} / \mathrm{mL})$ of 0.47 . For both cell lines, decrease in cell survival was statistically significant $(\mathrm{P}<0.001)$ as compared to the control. In samples treated with $32 \mu \mathrm{g} / \mathrm{mL}$ of extract practically no colonies were counted.

HTB140

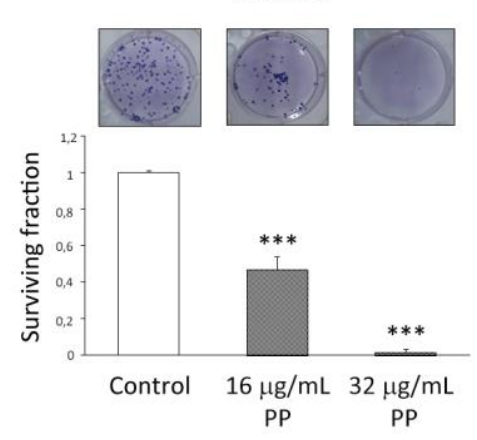

MCF7
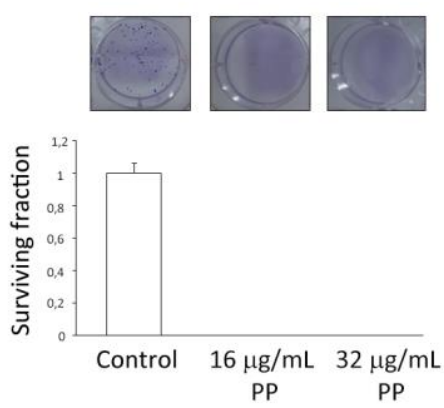

HTB177

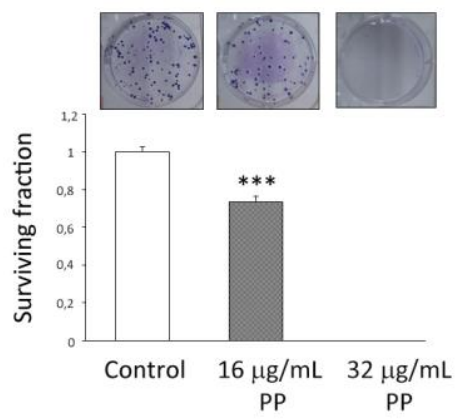

HCT116
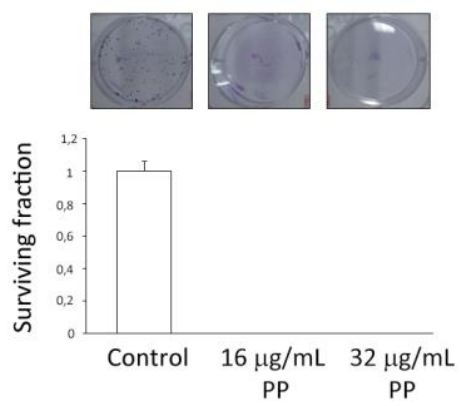

Figure 3. Survival of HTB140, HTB177, MCF7 and HCT116 cells after $24 \mathrm{~h}$ treatment with 16 and $32 \mu \mathrm{g} / \mathrm{mL}$ PP extract (PP) estimated by clonogenic assay

Results are presented as mean \pm SEM. Statistical significance compared to the control, $* 0.01<\mathrm{p}<0.05 ; * *$ $0.001<\mathrm{p}<0.01 ; * * * \mathrm{p}<0.001$. 


\subsubsection{Effects of PP Extract on Cell Cycle}

Cell cycle changes were monitored 24 and $48 \mathrm{~h}$ after treatment with $16 \mu \mathrm{g} / \mathrm{mL}$ of PP extract (Figure 4). We have tested this concentration because the PP extract at $32 \mu \mathrm{g} / \mathrm{mL}$ strongly inhibited cell survival as shown by clonogenic assay (Figure 3). As a response to the treatment, HTB140 cells expressed arrest in $\mathrm{G} 2 / \mathrm{M}$ cell cycle phase at $48 \mathrm{~h}$ time period $(\mathrm{p}<0.01)$. Moreover, at this time, the loss of HTB140 cells in S phase was also observed $(\mathrm{p}<0.05)$. Other cancer cell lines showed smaller changes in cell cycle distribution after the treatment. In HTB177 and MCF7 cells, a slight increase of $\mathrm{S}$ phase compared to control samples was observed at $48 \mathrm{~h}(\mathrm{p}<0.05)$, whilst HCT 116 showed minor G1 block at $48 \mathrm{~h}(\mathrm{p}<0.05)$.
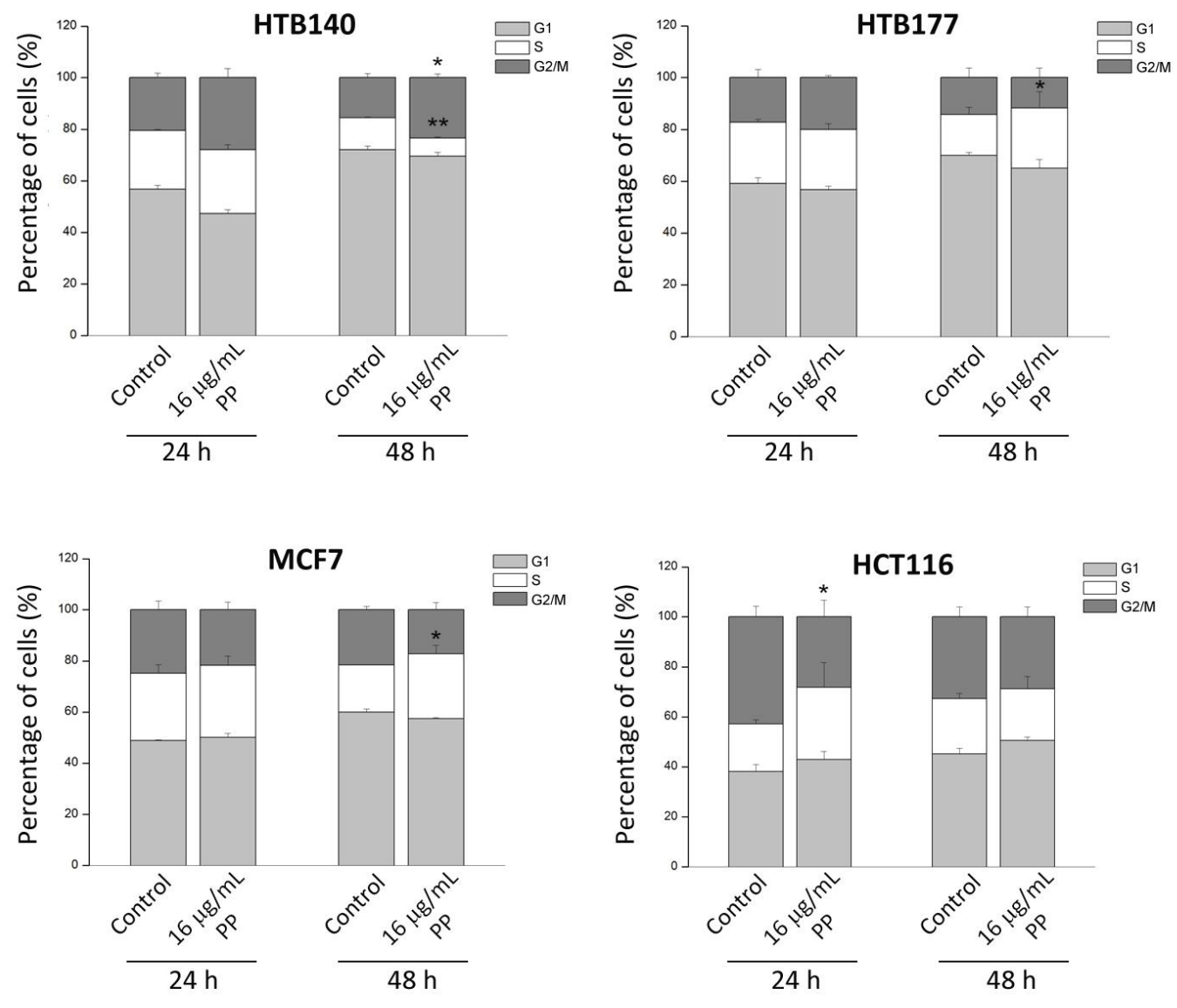

Figure 4. Cell cycle analysis of HTB140, HTB177, MCF7 and HCT116 cells after treatment with $16 \mu \mathrm{g} / \mathrm{mL}$ PP extract (PP). Analyses were performed at $24 \mathrm{~h}$ and $48 \mathrm{~h}$.

Results are expressed as mean \pm SEM. Statistical significance compared to the control, * $0.01<\mathrm{p}<0.05$; ** $0.001<\mathrm{p}<0.01 ; * * * \mathrm{p}<0.001$.

\subsubsection{Effects of PP Extract on Cancer Cell Migration}

Ability of cancer cells to migrate after wounding cell monolayer treated with $16 \mu \mathrm{g} / \mathrm{mL}$ PP extract is presented in Figure 5. In general, similar migratory ability was detected for HTB140 and HCT116 cells with no statistically significant changes detected between treated and untreated cells. PP extract had higher inhibitory effect on migration of MCF7 and HTB177 cells. For MCF7 cells, wound surface measured after the treatment was higher ( 72\%) compared to control (44\%). For 
HTB177 statistically significant changes in cell migration was observed with $\sim 72 \%$ wound surface compared to control cells $(\sim 20 \%)$.
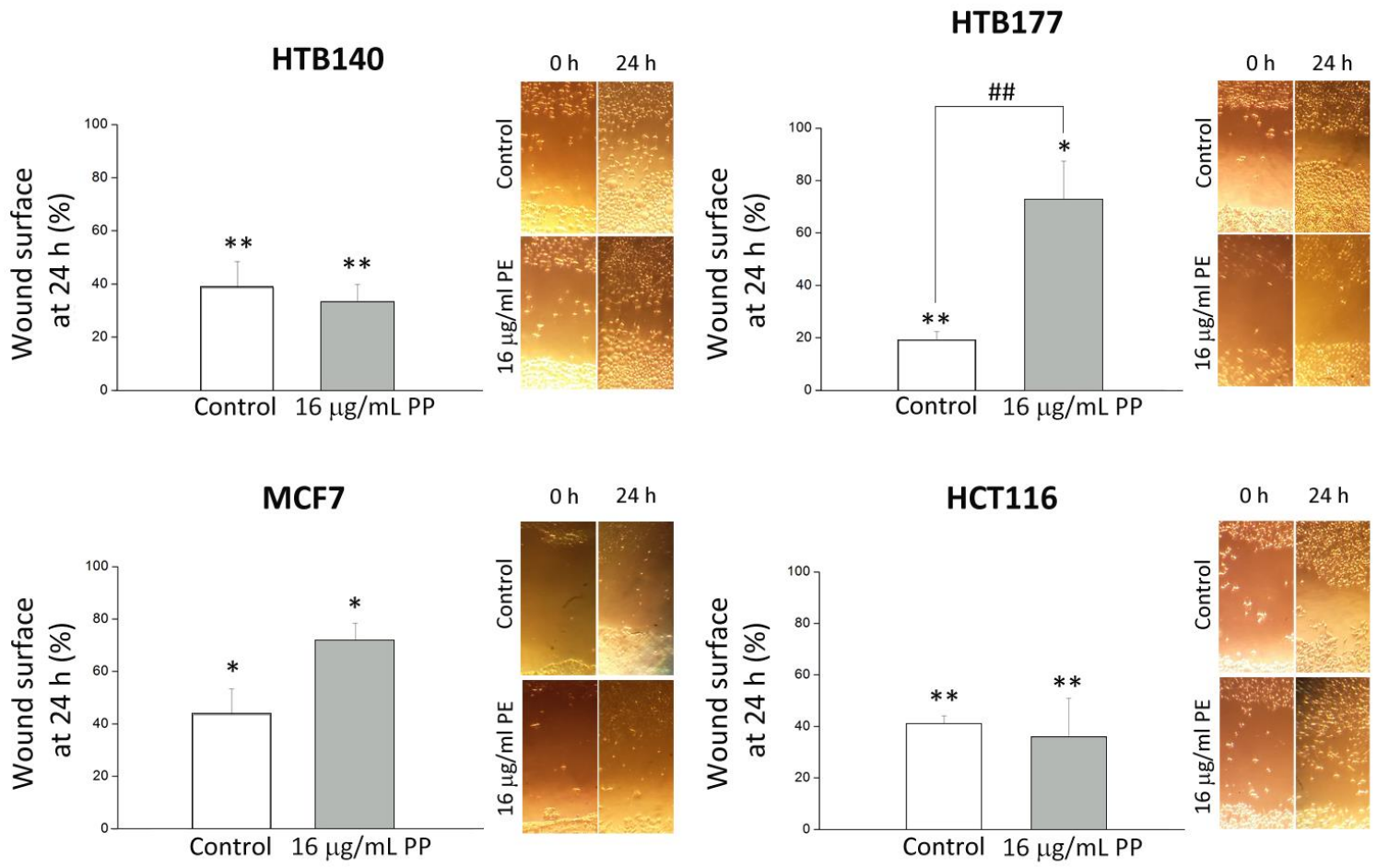

Figure 5. Migration of HTB140, HTB177, MCF7 and HCT116 cells after $24 \mathrm{~h}$ treatment with 16 $\mu \mathrm{g} / \mathrm{mL}$ PP extract (PP) estimated by wound healing assay. Photographs were taken at the time of extract administration $(0 \mathrm{~h})$ and $24 \mathrm{~h}$ later

Results are expressed as mean \pm SEM. Statistical significance of wound surface in untreated control $(24 \mathrm{~h}$ vs. 0 h) and in cells treated with $16 \mu \mathrm{g} / \mathrm{mL}$ PP $(24 \mathrm{~h}$ vs. $0 \mathrm{~h}),{ }^{*} 0.01<\mathrm{p}<0.05 ; * * 0.001<\mathrm{p}<0.01$; *** p <0.001.

\#Statistical significance of wound surface at $24 \mathrm{~h}$ (control vs. $16 \mu \mathrm{g} / \mathrm{mL}$ PP), \# $0.01<\mathrm{p}<0.05$; \#\# $0.001<\mathrm{p}$ $<0.01 ;$ \#\#\# p <0.001

\subsection{Previous Reports on Biological Activities of PP: Correlation to its Inhibitory Effects on Cancer Cells}

Pomegranate fruit is a rich source of biologically active compounds particularly phenolic compounds with ellagitannins, anthocyanins, proanthocyanidins, flavonoids as characteristic groups. Usually the inner part of the pomegranate fruit (arils with the seeds) is used in fresh condition or as a juice. The residue after juice production (hard pericarp together with yellow-white soft mesocarp) represents almost 50\% of whole fruit and it is routinely discarded as a waste [29]. Recently, a number of studies have been conducted showing that pomegranate peel is particularly rich in ellagitannis (mainly punicalin and punicalagin) and ellagic acid which are considered as potent biologically active phenolic compounds resulting in different beneficial effects on human health [11, $30,31]$. PP extract used in the present study was abundant in phenolic compounds. Compared with other authors' reports total phenolics content in our PP extract was higher. Hasnaoui et al. [32] reported lower amounts of total phenolics (205-276 mg GAE/g) similar to the results of Masci et al. [33] where in the pomegranate peel $255 \mathrm{mg}$ of total phenolics were determined. The amount of total flavonoids in our PP extract was similar to the results obtained by El-Said et al. [34] ranging from 6.32 to $7.98 \mathrm{mg} \mathrm{RE} / \mathrm{g}$. Differences in the content of total phenolics, tannins and flavonoids could be explained by different extraction conditions (type of the solvents, extraction method, temperature, duration of the extraction). Among individual compounds, ellagitannin punicalin was a dominant compound in our extract followed by ellagitannin punicalagin. Also, high amount of ellagic acid was present in PP extract. Punicalagin and ellagic acid were among major compounds in pomegranate 
peel analyzed by Masci et al. [33], where approximately twice as less amounts have been reported (28.45 mg/g and $11.85 \mathrm{mg} / \mathrm{g}$, respectively).

Previous data obtained by DPPH test showed good radical scavenging capacity of PP extract [35]. Moreover, pomegranate polyphenols revealed mixed pro- and ant oxidative effects in cultured cells $[17,18,36]$. With the aim of investigating the effects of PP extract in human cancer, four cancer cell lines of different tumor origin were used in this study. We have specially selected those cancer cells since they represent aggressive cancer models and display a high metastatic potential. For example, HCT116 colon cancer and HTB177 lung cancer cells are frequently used for investigation of molecular mechanisms of metastasis as well as anti-metastatic therapeutic strategies [37, 38]. HTB140 cell line represents aggressive form of melanoma which in general accounts for $65 \%$ of all deaths from skin cancer [39]. It has also been shown that MCF-7 breast cancer cells are able to metastasize to lungs, liver and spleen when injected into athymic nude mice [40].

According to the literature data, several studies investigated the effects of different fractions extracted from pomegranate on various cancer cell lines. Research conducted by Seeram et al. [41] evaluated antiproliferative activity of punicalagin, ellagic acid, total pomegranate tannin extract and pomegranate juice extract against several human oral, colon (including HCT116 cells) and prostate tumor cells. According to the results of this study, all pomegranate ingredients decreased cell viability in a dose-dependent manner in all cell lines tested. However, anti-proliferative activity of pomegranate juice is found to be superior compared to other tested purified polyphenols, which indicates that anti-carcinogenic properties can be attributed to synergistic effect of single active ingredients of pomegranate [41]. In the present study, we have shown that PP extract also has inhibitory effect on HCT116 colon cancer cell line which is probably due to combined activity of individual polyphenolic compounds of pomegranate peel. In the study of Dana et al. [42], black PP extract displayed anti-proliferative effects on B16F10 melanoma cells. Although active compound in black PP extract, which is responsible for the inhibitory effects on melanoma cell proliferation is not revealed, the authors proposed antioxidant effects and polyphenol content as responsible for the antiproliferative conduct of PP extract. Here we have also shown the inhibitory impact of PP extract on HTB140 melanoma cell line, although these cells responded to PP extract in lesser extend compared to other tested cell lines. Moreover, decreased viability of HTB177 lung cancer cells was also found after administration of PP extract. According to the published data, cytotoxic effect of PP extract was as well confirmed in human lung adenocarcinoma A549 cells [43]. Taking into account IC50 values and selectivity index determined in present study, MCF7 breast adenocarcinoma cells are the most sensitive, among tested cell lines, to the treatment with PP extract. High responsiveness of MCF7 cells to PP extract was previously reported in literature [43]. Moreover, it has been shown that PP extract reduces proliferation and induces apoptosis in MCF-7 cells depending on concentration applied and incubation time [44].

Considering the results assessed by clonogenic assay, MCF-7 and HCT166 cells were estimated as sensitive to selected doses of PP extract, contrary to HTB140 cells which were more resistant to the treatment (Figure 3). According to the results of Kasimsetty and colleagues [45], ellagitannins and urolithins from pomegranate juice decreases clonogenic efficiency of HT-29 colon cancer cells. They also demonstrated that these components induced cell cycle arrest in the G0/G1 and G2/M stages of the cell cycle and suggested that ellagitannins and urolithins from pomegranate juice could potentially limit the risk of colon cancer [45]. Survival data from the present study showed that the most resistant to PP extract were HTB177 cells with $\mathrm{SF}(16 \mu \mathrm{g} / \mathrm{mL})$ value of 0.74 . Also, HTB140 cells having $\mathrm{SF}(16 \mu \mathrm{g} / \mathrm{mL})$ of 0.47 and $\mathrm{SI}<2$ are considered to be resistant to the treatment. The most sensitive cell lines were MCF7 and HCT116 (Figure 3). These results are in accordance with the cytotoxicity data (Figure 1 and Table 3). Namely, as demonstrated by the increase in IC50 values, HTB177 and HTB140 cells showed slight recovery at the end of 48 hours compared to 24 hours. This is reflected in the higher survival rate compared to other cancer cell lines. Moreover, the MCF7 and HCT116 cells, which showed an increase in cell death at the end of 48 hours in the cytotoxicity assay, have also been inhibited by the extract in the clonogenic assay (Table 3, Figure 3). Major changes in cell cycle distribution upon the administration of PP extract were not detected. Namely, as presented in Figure 4, only HTB140 melanoma cells demonstrated changes in cell cycle distribution after the treatment with PP extract at $48 \mathrm{~h}$, with the increase of cells in $\mathrm{G} 2 / \mathrm{M}$ phase and the reduction in $\mathrm{S}$ phase compared to the untreated control. Literature data 
obtained for wound healing assay showed that PP extract has the potential to inhibit migration of prostate cancer cells which represents one of the critical steps of metastasis [46]. In the present study, PP extract exhibited the highest inhibitory potential against migration of the HTB177 cells compared to other cancer cell lines that were tested (Figure 5).

\section{Conclusion}

In the present study it is shown that aqueous-ethanol pomegranate peel extract (PP) is a potential anticancer agent with high selective for malignant cells compared to normal cell line. With the selectivity criteria of SI>2 estimated at $48 \mathrm{~h}$, three cancer cell lines were considered to be sensitive to the PP extract. With an exception of HTB140 cells, the degree of sensitivity to PP extract varied among the tested cell lines (HTB177 < HCT116 < MCF7), with MCF7 cells being the most sensitive. Obtained differences in biological responses among tested cell lines estimated through changes in clonogenic survival, cell cycle and migration after the administration of PP extract may be due to different nature of the cells. However, since oxidant properties of polyphenols may be both anti-oxidant and/or pro-oxidant based upon the cellular redox context, the exact mechanisms underlying biological responses of these cells to the PP extract still need to be addressed. The results reveal that PP extract exhibits good inhibitory effects on tested cancer cell lines and would be exploited in future experiments including combined treatments with other anti-cancer remedy, in particular radiation therapy.

\section{Acknowledgments}

This work was supported by the Ministry of Education, Science and Technological Development of the Republic of Serbia, project grants III 46013, 173046 and 171019.

\section{Conflicts of interest}

The authors declare that there are no conflicts of interest.

\section{ORCID}

Otilija Keta: 0000-0003-4974-8741

Milena Deljanin: 0000-0003-1080-8735

Vladana Petković: 0000-0003-0538-3322

Gordana Zdunić: 0000-0002-5793-3739

Teodora Janković: 0000-0002-5895-7214

Jelena Živković: 0000-0002-5142-1361

Aleksandra Ristić-Fira: 0000-0002-8002-8470

Ivan Petrović: 0000-0001-5553-3160

Katarina Šavikin 0000-0002-2086-9593

\section{References}

[1] J. S. Jurenka (2008). Therapeutic applications of pomegranate (Punica granatum L.): a review, Altern. Med. Rev. 13, 128-144.

[2] S. Basiri (2015). Evaluation of antioxidant and antiradical properties of Pomegranate (Punica granatum L.) seed and defatted seed extracts, J. Food Sci. Technol. 52, 1117-1123.

[3] P. Langley (2000) Why a pomegranate? BMJ 321, 1153-1154.

[4] S. P. Balasubramani, J. Mohan, A. Chatterjee, E. Patnaik, S. K. Kukkupuni, U. Nongthomba and P. Venkatasubramanian (2014). Pomegranate juice enhances healthy lifespan in Drosophila melanogaster: An exploratory study, Front. Public Health. 2, 245 doi: 10.3389/fpubh.2014.00245. eCollection 2014.

[5] T. Ismail, P. Sestili and S. Akhtar (2012). Pomegranate peel and fruit extracts: a review of potential anti-inflammatory and anti-infective effects, J. Ethnopharmacol. 143, 397-405. 
[6] S. Hasani-Ranjbar, B. Larijani and M. Abdollahi (2008). A systematic review of Iranian medicinal plants useful in diabetes mellitus, Arch. Med. Sci. 4, 285-292.

[7] M. Aviram and M. Rosenblat (2013). Pomegranate for your cardiovascular health, Rambam. Maimonides Med. J. 4, e0013.

[8] N. D. Kim, R. Mehta, W. Yu, I. Neeman, T. Livney, A. Amichay, D. Poirier, P. Nicholls, A. Kirby, W. Jiang, R. Mansel, C. Ramachandran, T. Rabi, B. Kaplan and E. Lansky (2002). Chemopreventive and adjuvant therapeutic potential of pomegranate (Punica granatum) for human breast cancer, Breast Cancer Res. Treat. 71, 203-217.

[9] S. Kote, S. Kote and L. Nagesh (2011). Effect of pomegranate juice on dental plaque microorganisms (streptococci and lactobacilli), Anc. Sci. Life 31, 49-51.

[10] M. N. Aslam, E. P. Lansky and J. Varani (2006). Pomegranate as a cosmeceutical source: pomegranate fractions promote proliferation and procollagen synthesis and inhibit matrix metalloproteinase-1 production in human skin cells, J. Ethnopharmacol. 103, 311-318.

[11] E. P. Lansky and R. A. Newman (2007). Punica granatum (pomegranate) and its potential for prevention and treatment of inflammation and cancer, J. Ethnopharmacol. 109, 177-206.

[12] M. I. Gil, F. A. Tomás-Barberián, B. Hess-Pierce, D. M. Holcroft and A. A. Kader (2000). Antioxidant activity of pomegranate juice and its relationship with phenolic composition and processing, J. Agric. Food Chem. 48, 4581-4589.

[13] I. Stojanović, K. Šavikin, N. Đedović, J. Živković, T. Saksida, M. Momčilović, I. Koprivica, M. Vujičić, S. Stanisavljević, Đ. Miljković and N. Menković (2017). Pomegranate peel extract ameliorates autoimmunity in animal models of multiple sclerosis and type 1 diabetes, J. Funct. Foods. 35, 522-530.

[14] S. Akhtar, T. Ismail, D. Fraternale and P. Sestili (2015). Pomegranate peel and peel extracts: chemistry and food features, Food Chem. 174, 417-425.

[15] N. Seeram, R. Lee, M. Hardy and D. Heber (2005). Rapid large scale purification of ellagitannins from pomegranate husk, a by-product of the commercial juice industry, Sep. Purif. Technol. 41, 4955.

[16] A. Günes-Bayir, A. Kocyigit and E. M. Güler (2018). In vitro effects of two major phenolic compounds from the family Lamiaceae plants on the human gastric carcinoma cells, Toxicol. Ind. Health. 34, 525-539.

[17] A. Kocyigit and E. M. Guler (2017). Curcumin induce DNA damage and apoptosis through generation of reactive oxygen species and reducing mitochondrial membrane potential in melanoma cancer cells. Cell Mol Biol (Noisy-le-grand) 63, 97-105.

[18] A. Günes-Bayir, H. S. Kiziltan, A. Kocyigit, E. M. Güler, E. Karataş and A. Toprak (2017). Effects of natural phenolic compound carvacrol on the human gastric adenocarcinoma (AGS) cells in vitro, Anticancer Drugs. 28, 522-530.

[19] M. J. Thun, J. O. Delancey, M. M. Center, A. Jemal and E. M Ward (2010). The global burden of cancer: priorities for prevention, Carcinogenesis 31, 100-110.

[20] E. Turrini, L. Ferruzzi and C. Fimognari (2015). Potential effects of pomegranate polyphenols in cancer prevention and therapy, Oxid. Med. Cell Longev. 2015, 938475.

[21] M. Arruebo, N. Vilaboa, B. Sáez-Gutierrez, J. Lambea, A. Tres, M. Valladares and A. GonzálezFernández (2011). Assessment of the evolution of cancer treatment therapies, Cancers (Basel) 3, 3279-3330.

[22] O. Keta, T. Bulat, I. Golić, S. Incerti, A. Korać, I. Petrović and A. Ristić-Fira (2016). The impact of autophagy on cell death modalities in CRL-5876 lung adenocarcinoma cells after their exposure to $\gamma$ rays and/or erlotinib, Cell Biol. Toxicol. 32, 83-101.

[23] X. J. Liang, C. Chen, Y. Zhao and P. C. Wang (2010). Circumventing tumor resistance to chemotherapy by nanotechnology, Methods Mol. Biol. 596, 467-488.

[24] B. Hazra, S. Ghosh, A. Kumar and B. N. Pandey (2011). The prospective role of plant products in radiotherapy of cancer: a current overview, Front. Pharmacol. 2, 94. doi: 10.3389/fphar.2011.00094. eCollection 2011.

[25] A. K. Garg, T. A. Buchholz and B. B. Aggrawal (2005). Chemosensitization and radiosensitization of tumors by plant polyphenols, Antioxid. Redox Signal. 7, 1630-1647.

[26] P. G. Waterman and S. Mole. Analysis of phenolic plant metabolites. Oxford: Blackwell Scientific Publication, 1994.

[27] European Pharmacopoeia, (7th ed.). (2011). Council of Europe, Strasbourg.

[28] J. Zhishen, T. Mengcheng and W. Jianming (1999). The determination of flavonoid contents in mulberry and their scavenging effects on superoxide radicals, Food Chem. 64, 555-559. 
[29] F. A. Al-Said, L. U. Opara and R. A. Al-Yahayi (2009). Psysico-chemical and textural quality attributes of pomegranate cultivars (Punica granatum L.) grown in the Sultanate of Oman. J. Food Eng. 90, 129-134.

[30] E. H. Endo, D. A. Cortez, T. Ueda-Nakamura, C. V. Nakamura and B. P. Diasfilho (2010). Potent antifungal activity of extracts and pure compound isolated from pomegranate peels and synergism with fluconazole against Candida albicans, Res. Microbiol. 161, 534-540.

[31] C. Usta, S. Ozdemir, M. Schiariti and P. E. Puddu (2013). The pharmacological use of ellagic acidrich pomegranate fruit, Int. J. Food Sci. Nutr. 64, 907-913.

[32] N. Hasnaoui, B. Watheket and A. Jiménez-araujo (2014). Valorization of pomegranate peel from 12 cultivars: Dietary fibre composition, antioxidant capacity and functional properties, Food Chem. 160, 196-203.

[33] A. Masci, A. Coccia, E. Lendaro, L. Mosca, P. Paolicelli and S. Cesa (2016). Evaluation of different extraction methods from pomegranate whole fruit or peels and the antioxidant and antiproliferative activity of the polyphenolic fraction, Food Chem. 202, 59-69.

[34] M. M. El-Said, H. F. Haggag, H. M. Fakhr El-Din, A. S. Gad and A. M. Farahat (2014). Antioxidant activities and physical properties of stirred yoghurt fortified with pomegranate peel extracts, Annal. Agric. Sci. 59, 207-212.

[35] K. Šavikin, J. Živković, A. Alimpić, G. Zdunić, T. Janković, S. Duletić Laušević and N. Menković (2018). Activity guided fractionation of pomegranate extract and its antioxidant, antidiabetic and antineurodegenerative properties, Ind. Crops. Prod. 113, 142-149.

[36] F. Danesi, P. A. Kroon, S. Saha, D. de Biase, L. F D'Antuono and A. Bordoni. Mixed pro- and antioxidative effects of pomegranate polyphenols in cultured cells, Int. J. Mol. Sci. 15, 19458-19471.

[37] K. Ishizu, N. Sunose, K. Yamazaki, T. Tsuruo, S. Sadahiro, H. Makuuchi and T. Yamori (2007). Development and characterization of a model of liver metastasis using human colon cancer HCT-116 cells, Biol. Pharm. Bull. 30, 1779-1183.

[38] S. H. Wu, Y. T. Hsiao, C. L. Kuo, F. S. Yu, S. C. Hsu, P. P. Wu, J. C. Chen, T. C. Hsia, H. C. Liu, W. H. Hsu and J. G. Chung (2015). Bufalin inhibits NCI-H460 human lung cancer cell metastasis in vitro by inhibiting MAPKs, MMPs, and NF-кB pathways, Am. J. Chin. Med. 43, 1247-1264.

[39] R. Shashanka and B. R. Smitha (2012). Head and neck melanoma, ISRN Surg. 2012, 948302.

[40] S. M. Shafie and L. A. Liotta (1980). Formation of metastasis by human breast carcinoma cells (MCF7) in nude mice, Cancer Lett. 11, 81-87.

[41] N. P. Seeram, L. S. Adams, S. M. Henning, Y. Niu, Y. Zhang, M. G. Nair, and D. Heber (2005). In vitro antiproliferative, apoptotic and antioxidant activities of punicalagin, ellagic acid and a total pomegranate tannin extract are enhanced in combination with other polyphenols as found in pomegranate juice, J. Nutr. Biochem. 16, 360-367.

[42] N. Dana, Sh. H. Javanmard and L. Rafiee (2015). Antiangiogenic and antiproliferative effects of black pomegranate peel extract on melanoma cell line, Res. Pharm. Sci. 10, 117-124.

[43] S. Modaeinama, M. Abasi, M. M. Abbasi and R Jahanban-Esfahlan (2015). Anti tumoral properties of punica granatum (pomegranate) peel extract on different human cancer cells, Asian Pac. J. Cancer Prev. 16, 5697-5701.

[44] M. Dikmen, N. Ozturk and Y. Ozturk (2011). The antioxidant potency of Punica granatum L. Fruit peel reduces cell proliferation and induces apoptosis on breast cancer. J. Med. Food. 14, 1638-1646.

[45] S. G. Kasimsetty, D. Bialonska, M. K. Reddy, G. Ma, S. I. Khan and D. Ferreira (2010). Colon cancer chemopreventive activities of pomegranate ellagitannins and urolithins, J. Agric. Food Chem. 58, 2180-2187.

[46] Y. Deng, Y. Li, F. Yang, A. Zeng, S. Yang, Y. Luo, Y. Zhang,Y. Xie, T. Ye, Y. Xia and W. Yin (2017). The extract from Punica granatum (pomegranate) peel induces apoptosis and impairs metastasis in prostate cancer cells, Biomed. Pharmacother. 93, 976-984.

\section{A C G \\ publications \\ (c) 2020 ACG Publications}

